\title{
A Christmas Carol
}

\section{Gregory A Petsko}

Address: Rosenstiel Basic Medical Sciences Research Center, Brandeis University, Waltham, MA 02454-9110, USA.

E-mail: petsko@brandeis.edu

Published: 28 December 200I

Genome Biology 200I, 3(I):comment I001.1-1001.2

The electronic version of this article is the complete one and can be found online at http://genomebiology.com/200I/3/I/comment/I00 I

(c) BioMed Central Ltd (Print ISSN 1465-6906; Online ISSN 1465-69|4)

No, this isn't another story about some selfish miserly person learning the value of kindness and generosity. Charles Dickens told that particular tale better than anyone before or since. But it is a story with a happy ending, and a moral that I believe is worth remembering. It's a story about the value of basic, hypothesis-driven research. I think the story is important because in the age of genomics such research is increasingly taken for granted, if not slighted. Discovery-driven research is so much flashier, so much easier to sell to funding agencies and government officials since it is, by definition, guaranteed to produce results. By discovery-driven research I mean research that seeks simply to collect data: the sequencing of the human genome is the obvious example. Another example would be any of the structural genomics or proteomics initiatives; these are, in essence, cataloging exercises. I don't mean to disparage such activity - in biology it has a long and honorable history. Charles Darwin's expedition on the Beagle was a cataloging exercise, and from it sprang the single most important tenet in the life sciences, the theory of evolution by means of natural selection. There is nothing at all wrong with cataloging, especially if someone with the genius of Darwin (or, to be fair, Alfred Russell Wallace) peruses the catalog.

Then there is targeted research, research that has a specific practical objective. The war on cancer (by the way, I haven't read the newspaper lately - who won?) and many other clinical research programs would fall into this category, as would the agricultural research that led to the Green Revolution of the mid-nineteenth century. This kind of research can be extremely important and often brings great benefits to mankind. Consequently, it is usually well-supported and easily justified to press and public. Carried to extremes, it produces work that has as its objective the completion of some clever stunt. Occasionally it results in technology that is useful to many other scientists, but more often it yields difficult, expensive, cumbersome technology that is useful only to its inventors. I've read many papers in this vein, and in the end they only leave me with an impression of the cleverness of their authors, which, I suppose, is precisely the impression they were meant to leave. Rarely have they taught me anything about how the world works, and I find it somewhat disheartening that such work is so widely publicized and so well rewarded these days. Our story isn't about targeted research, whether valuable or self-indulgent, nor about discoverydriven research. It's about the other kind, the kind that sometimes seems to be going out of style in biology under the onslaught of genomics.

Barnett Rosenberg wasn't trying to cure cancer. He wasn't working on cancer. He wasn't working on any diseaserelated problem. He wasn't even working with human cells. All he was trying to do was to test a hypothesis about what would happen when dividing bacteria were placed in a strong electric field. Yet he may have saved the lives of more cancer patients than most of the cancer researchers in the world put together. Our story begins one day in 1964 in his laboratory at Michigan State University. That day Barnett Rosenberg (Barney, to his friends) put a suspension of Escherichia coli cells between two platinum electrodes to see what would happen. He had no more practical goal than to satisfy his own curiosity about a hypothesis he had formulated. He was a microbiologist, and the behavior of bacteria was his research interest. He knew that when a bacterial cell divides the cell's DNA has to become organized, and he hypothesized that a strong electric field might interfere with the arrangement of the highly charged, precisely oriented chromosome. So he put a continuous culture of $E$. coli cells in buffered medium between two platinum electrodes and turned on the current.

What he saw surprised him. Cell division was inhibited, but in addition the bacteria, which are normally shaped like small rods, grew into long filaments, up to 300 times their normal length. Now our story actually has several morals, but a very important one is that in science there is no such thing as useless information. Barney Rosenberg happened to know that $E$. coli cells became filamentous under certain 
other conditions, including exposure to certain anti-tumor drugs. It didn't take long for him to establish that it wasn't the electric field itself that was producing the filamentous behavior. A chemical substance in the solution was responsible, but the effect required that group VIIIb metal electrodes be used to generate the electric field - no other electrodes would do - suggesting that the substance was being generated electrochemically from components in the media plus the platinum metal.

Many scientific journals today seem to function largely as press release vehicles, but Barney's 1965 Nature paper (205:698-699), in which he describes these studies, is an experimentalist's delight. Not only does he give enough information to enable anyone to repeat the work - the minimum standard of a scientific publication but one that is seldom met any more - he tells the story of the reasoning process he followed. After further studies he was able to isolate the active substance: he had accidentally synthesized Peyrone's salt: cis-dichlorodiammine-platinum(II), also known as cisplatin. A square planar platinum compound with two chlorines and two ammines coordinated to the metal ion, cisplatin was first described in the 1800 s but had never been tested as an antibacterial or anti-tumor agent before; after all, everyone knew that transition metal complexes were poisonous. That had been the conventional wisdom for over a hundred years. But remember, Barney knew that some anti-tumor agents produced the same effects on bacterial cells that cisplatin seemed to, so in 1968 he made what he later called the "purely intuitive jump" to test this complex for anticancer activity in a mouse tumor model system. He needed help to carry out these tests because he had never done anything of the kind before. He got that help from Virginia Mansour, and on April 261969 they published in Nature (222:385-386) the astonishing result that cisplatin completely inhibited the development of the solid Sarcoma-180 tumor in mice.

Now, a lot of stories start out like that. If a hundred years of cancer research has taught us anything, it is that if you must get cancer, you want to be a mouse, because we can cure cancer in mice. Curing it in people is immensely harder, and most promising therapies fail at exactly the transition from mouse to man. So it took Barney some time to find clinicians who believed in his work enough to try cisplatin in human patients. But within two years, Harris and others had carried out preliminary clinical trials showing anticancer activity in several patients; and by 1973 it was clear from work by Wallace, Wiltshaw and Carr that cisplatin had a particularly high degree of activity against testicular and ovarian cancers, diseases considered terminal and unresponsive to the best prior therapies. Kidney toxicity hampered the deployment of the drug for a time, but Hayes and associates eventually found that the simple trick of hydrating the patient to wash the toxic material out of the kidneys markedly diminished this side effect.
Our story concludes in the Christmas season of 2001, thirty years after the first human trials of Barney's discovery. Cisplatin has become the best-selling cancer drug in the world. It is a complete cure for testicular cancer if the disease is detected early enough. It is one of the most effective drugs against melanoma and non-small-cell lung carcinoma, and in combination therapy it also shows considerable promise against ovarian cancers. Well, I promised you a happy ending. Now for the other moral. I have nothing against big, targeted or discovery-driven science programs per se (although I do object, strongly, to such programs being oversold to a trusting, anxious public). These endeavors have produced much useful information and keep many scientists off the unemployment rolls - both laudable achievements. And I can understand the political pressures that drive the US National Institutes of Health and its orthologs in other countries to nudge biological research towards working more with human cells, and with human proteins, and on human diseases. But I don't see how a 'War on Cancer' or targeted biomedical research, in any academic institution or pharmaceutical laboratory, ever gets you to cisplatin. This is not a compound that would ever be found in any combinatorial library or collection of natural products. There isn't a single atom of carbon in it. No medicinal chemist would ever have thought of it. No targeted research program would have investigated it. No discovery-driven program of chemical genomics would have included it. Cisplatin came from outside the box - in fact, so far outside that the box wasn't even visible; it came from a place no one would, at that time, have dreamt of looking in for an anticancer drug.

We can, and should, focus teams of well-trained researchers on specific goals such as unraveling the mechanisms of tumorgenesis. We can, and should, try to coordinate and plan our disease-fighting efforts so that our resources are spent efficiently. But we must never forget that Barney Rosenberg, with his bacterial cells and electrodes, and his curiosity, imagination and persistence, may have saved the lives of more people than most of the cancer researchers in the world put together. So, the next time some Scrooge bahhumbugs basic research, or asks you what investigator-initiated, hypothesis-driven science is good for, tell them Barney's story. 